\title{
User Reactions to Search Engines Logos: Investigating Brand Knowledge of web Search Engines
}

\author{
Bernard J. Jansen \\ College of Information Sciences and Technology \\ The Pennsylvania State University \\ University Park, Pennsylvania 16802 \\ jjansen@acm.org \\ Lu Zhang \\ School of Hospitality Management \\ The Pennsylvania State University \\ University Park, PA 16802-1307 \\ 1xz152@psu.edu \\ Anna S. Mattila \\ Marriott Professor of Lodging Management \\ School of Hospitality Management \\ The Pennsylvania State University \\ University Park, PA 16802-1307 \\ asm6@psu.edu
}

\begin{abstract}
In this work, we investigate consumer reaction to web search engine logos. Our research is motivated by a small number of search engines dominating a market in which there are little switching costs. The major research goal is to investigate the effect that brand logos have on search engine brand knowledge, which includes brand image and brand awareness. To investigate this goal, we employ a survey of 207 participants and use a mixed method approach of sentiment analysis and mutual information statistic to investigate our research questions. Our findings reveal that some search engines have logos that do not communicate a clear meaning, resulting in a confused brand message. Brand image varies among the top search engines, with consumers possessing generally extremely positive or negative brand opinions. Google elicited a string of positive comments from the participants, to the point of several uses of the term 'love.' This is in line with the ultimate brand equity that Google has achieved (i.e., the generic term
\end{abstract}


for web search). Most of the other search engines, including Microsoft, had primarily negative terms associated with them, although AOL, Ask, and Yahoo! had a mix of both positive and negative comments. Implications are that the brand logo may be an important interplay component with the technology for both established search engines and those entering the market.

Keywords: brand knowledge, brand image, brand awareness, brand logos, web search engines

\section{INTRODUCTION}

With search engines the major entry points to the web for ecommerce transactions [1], the search engine marketplace is a critical area of study, including the reasons underlying consumers' choice of which search engine to use. Evaluations of search engines report that performance is similar [2] based on precision, which is the ratio of relevant documents to the total number of documents returned at some point in the results listing. The interfaces of the major search engines are generally comparable Entry into the search engine market is open. Switching cost among search engines for consumers is near zero. Therefore, it is somewhat of a mystery why the search engine market is so concentrated, with a few search engines dominating the market. In a related vein, it is also interesting to speculate on why is it so difficult for new entries or those engines rebranding themselves to gain a significant user base. Certainly, a variety of subjective, affective, cognitive, and contextual factors affect users' views of an engine's performance. One possible explanation is brand knowledge, composed of brand awareness and brand image, which has been shown to effect users' subjective performance evaluation [3]. However, the investigation of how these branding concepts affect consumer perception of web search engines is extremely limited. This is especially true in regards to the effect of a search engine's logo, which is the focus of this research.

What is the level of brand awareness for the various search engine companies? How does the design of search engine logos influence users' perception of the search engine? What are the 
implications of user reactions to logos for branding in the search engine market? These are some of the questions that motivate our research into understanding user's views of search engines from a branding perspective. An understanding of the effect of brand image, most notably the effect of a logo, on consumer perception of a search engine may partially explain the reason for the concentration of the search engine marketing and the difficulty faced by entrants into this marketplace. This research could also shed light on similar marketplaces with concentration of firms, little consumer switching costs, and similar product performance.

We first review the literature in the branding area to provide grounding for our research questions. This is followed by a discussion of the methodologies we used to empirically investigate our research questions. After analyzing the data, we discuss the results. We then present the theoretical and practical implications of the findings. Finally, we explore the limitations, strengths, and future research.

\section{LITERATURE REVIEW}

The conceptual basis for this research is branding. At its most basic, a brand is the intangible sum of an organization's attributes. Brands have a significant impact on consumers' perception and choice of a product. Therefore, branding is a central priority of successful companies, and one of most valuable assets of a firm [4]. Managed effectively, branding can create a positive image of a firm's products or services and result in increased customer loyalty.

One can understand brands from a variety of perspectives, including tangible brand features, such as name, design, or symbol, and company website. The intangible features of brands, such as values, ideas, and personality, are included in a broad brand perspective [5]. The primary component of branding that we investigate in this research is brand image and brand awareness as subcomponents of brand 
knowledge. We begin by reviewing key branding concepts and relating them to the domain of web search engines.

\subsection{Branding Components}

There are several components of branding.

Brand knowledge is a function or an associative network memory model composed of two subcomponents of brand awareness and brand image [6]. Using brand knowledge, one can gauge the differential effect of customer responses to brand marketing effort. Brand knowledge affects the consumers brand relationship (composed of brand satisfaction and brand trust). Therefore, brand awareness and brand image are key elements for any firm.

Brand awareness refers to the strength of the brand in memory of a consumer and is measured by consumers' ability to identify the brand under different conditions [7]. Brand awareness consists of brand recognition and brand recall. Brand recognition is the consumers' ability to confirm prior exposure to the brand when given the brand directly as a cue [6]. Brand recall is consumers' ability to retrieve the brand when given the product category, the needs fulfilled by the category, or some other type of probe as a cue [6]. Therefore, companies want consumers to recognize and recall their brand, aided or unaided. Brand image is perceptions about a brand as reflected by the brand associations held in a consumer's memory. Brand image has been extensively employed in various brand equity frameworks $[6]$.

These components are some of key nuanced aspects of branding in the mind of the consumer, which compose the concept of a company's brand. 


\subsection{Branding Logo}

Many of these aspects of a brand are encapsulated within the brand logo.

Brand logo is an essential component of brand image, and it can be a stimulus brand recognition. A logo refers to the graphic and textual design of an image that a company uses, with or without its name, to identify itself or its products. It is the shorthand for everything for which the brand stands [8]. As a key branding component, logos are significant company assets that firms spend enormous amounts of time and money promoting [8]. Logos can help consumers and potential consumers transcend international boundaries and language barriers because logos communicate visually [9]. The image of a brand has been shown to stimulate areas of the human brain [10], pointing to the need of neuromarketing [11].

Selame and Selame [12] define a logo in a broad sense, as a firm's visual statement to the world of who the company is, what the company is about, and how the company views itself. Chevalier and Mazzalovo [13] state that the logo plays a role in customer - company relations due to its informational content for the consumer prior to and for the perception by the consumer after a purchase. Buttle and Westoby [14] discuss the use of text in the processing of logos for the consumer, with many search engines including text in their logos. Van den Bosch, de Jong and Elving [15] state that a firm's logo represents the company's both current results and the future ambitions. The logo is a symbol for the company as a whole in the marketplace [16]. As such, a logo can be an efficient mechanism for communicating the desired company identity, which can take a long time to build or shed.

Yet, there is little systematic research on the effect of logo design on brand evaluation and preference [17] in the search engine area. In fact, there appears to be little use of marketing research in the design of web interfaces [18]. This lack of research is surprising. In the online domain, the immediate availability of the Internet is making logo design more important than ever before. For 
example, top management is turning its focus to how people respond to company logos seen on the computer screen [19]. Powerful and especially attractive logos may be expected to attract the attention of potential online customers [20]. For search engines, the logo is one of the most important associations of brand image as a visual cue for potential searchers as customers. Research shows that trust perception is an important element in ecommerce [21], which a logo can provide [22]. Most search engines have their logo prominently displayed on their website. Therefore positive branding is certainly perceived as a competitive advantage for a search engine, while negative branding can competitively harm a firm. Figure 1 illustrates the conceptual impact of a brand logo within an overall branding framework.

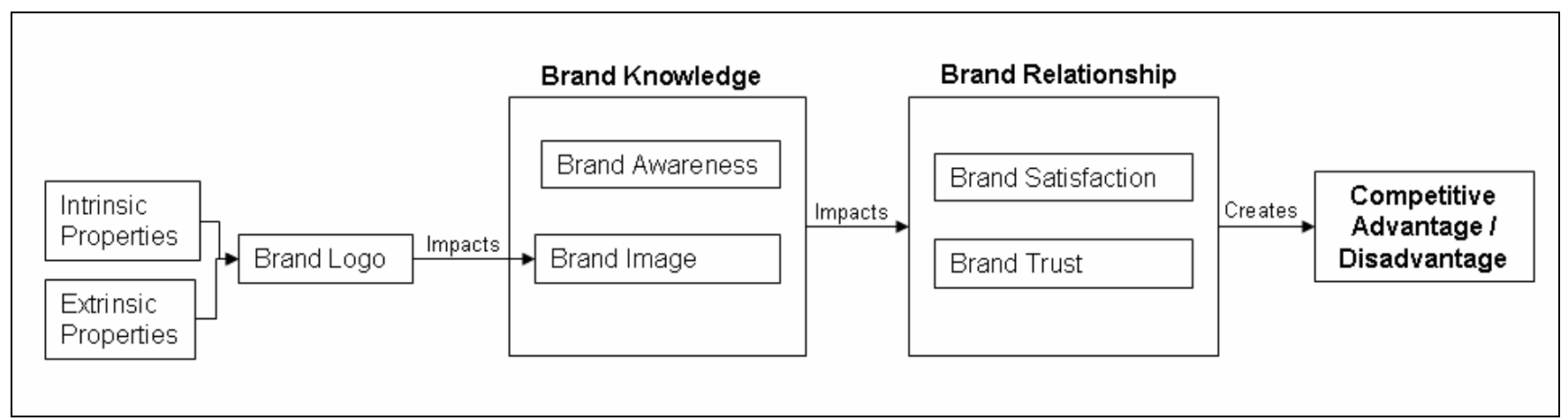

Figure 1: Effect of Brand Logo Within an Overall Branding Framework.

\subsection{Branding in the Search Engine Marketplace}

Although branding is well researched in the general marketing literature, the effect of branding in the search engine area has received limited consideration [23], although it has received some acknowledgement. Jansen, Zhang, and Schultz [3] investigated the effect of brands, specifically brand awareness, on the process of evaluating search engine results during web searches. The researchers proposed that branding affects web searches during four stages: (1) search engine selection, (2) search engine results page evaluation, (3) individual link evaluation, and (4) evaluation of the landing page. However, their research investigated only one aspect of branding, which is brand awareness. Therefore, 
the validity of the overall model is not empirically supported. The research presented here is a step toward further evaluation of the proposed model.

In a replication study of [3], Bailey et al. [24] reported no significant preference for one brand name search engine over the other engines in the study. The search engine results, however, were branded only with a name, rather than colors and logos of the specific search engines. So, the study did not investigate the full context of brand awareness. Except for these two articles, we located no published works investigating brands in the critically important search engine market.

\section{RESEARCH QUESTIONS}

In the present study, we investigate the subcomponents of brand knowledge (i.e., brand awareness and brand image) in the search engine marketplace, in particular examining the reaction to web search engine logos and then the search engines themselves. Such research is important, as it may assist in understanding the composition of the search engine market.

One key element of any search engine is getting new searchers and enticing existing searchers to return. Therefore, the searcher's reaction to an engine's logo may be a factor in this decision process via cognitive and affective reactions to the logo design and message. As such, this research contributes to a growing body of work in consumer - company relationships at the psychological level that marketers desire [25]. We investigate the role of search engine logos as a contributing factor in this relationship.

Research question 1: What are the different levels of brand awareness for the various major search engines in potential consumers?

This research question serves as a baseline for the investigation of search engine logos. We are interested in the overall brand awareness of competitors in the search engine. Brand awareness plays an 
important role in consumer decision making. It increases the likelihood that the brand will be a viable choice for consumers [6]. The set of choices is referred to the as the consideration set, which is generally a handful of brands that receive serious consideration for purchase or use. Brand awareness also influences the formation and strength of brand associations in brand image and affects decisions even if there are no other brand associations. In the search engine area, we propose that brand awareness can influence customers' selection of web search engines when consumers think about the overall product category.

At the time of the writing of this article, Google is the leader in the search engine market. However, this has not always been so and may not be so in the future. New search engines are continually entering the marketplace. Established search engines are attempting to rebrand themselves. Therefore, it is important to understand the effect of brand awareness to shed light on consumer sentiment and possible changes in the marketplace.

To measure brand awareness, there are three general approaches: top of mind, spontaneous, and aided recall. Top of mind has emerged as one of the best 'predictors' of brand choice, as shown in Axelrod's [26] longitudinal study, which was validated in follow-on studies [27]. Percy and Rossiter [7] argued that when options are present at the time of purchase (e.g., brands on a supermarket shelf) then aided recall is most relevant. However, when options are not available, spontaneous awareness should be used. At the decision-making point of search engine selection, no options are present for users. Therefore, in this study, we adopted spontaneous recall rather than aided recall or top of mind, since a consumer generally has no presented options when making a search engine selection.

Research question 2: Do different search engine logos cause different brand responses in potential consumers? 
For this research question, we are interested in a narrow focus of brand image, specifically a potential customer's reaction to a search engine logo. A logo can evoke both positive and negative reactions to the brand with little or no processing of information [28]. Successful logo designs speed recognition of a company or brand; elicit familiarity and positive effective reactions, which can transfer from the logo to the product or company; and evoke the same intended meaning across people [29]. As one of the major methods for communication of a company's image, logos can attract consumer attention and speed company recognition.

However, a company logo can also invoke negative responses and be damaging to a company's brand image [30]. Also, a logo can evoke associated meanings in potential consumers, which may be detrimental to a search engine's branding message. Henderson and Cote [30] note that the two necessary and sufficient conditions for a company logo to add value are (1) stakeholders correctly recognize the logo and (2) stakeholders correctly associate the logo with the company. Naturally, this assumes that the consumer reaction to the logo is positive. It is this association that we evaluate with this research question.

Research question 3: What are the brand perceptions for different search engines in potential consumers?

For this research question, we are interested in branding from the customer or brand recipient's perspective. For a brand recipient, such as a web search engine user, a brand may exert an identification image, a discrimination function, a quality assurance, a prestige, or a trust function [31]. As shown by [3], the search engine brand has an effect on affective judgments by the searcher of search engine performance. Although a visual shape (like a logo) has inherent meaning, the use of a logo by a company may strengthen or weaken this meaning by the association between the logo and the company. Riel and Ban [32] postulate that each company logo has a set of both intrinsic and extrinsic properties 
that affect an individual reaction. They define intrinsic properties as resulting directly from a confrontation with the logo itself and extrinsic properties as originating from the associations with the company behind the logo. Therefore, gauging reactions to search engine logos may shed a nuanced aspect of consumer perceptive of a search engine, rather than directly asking for comments on performance.

\section{METHODOLOGY}

Our methodology is mixed methods, although our approach has an overall qualitative bend. Given that the effect of logos in the search engine marketplace has not been previously investigated, the use of qualitative methods is appropriate as we attempt to develop a better and profound understanding of the problem space [33].

\subsection{Data Collection}

We employed a survey method to empirically investigate our research questions. We surveyed 207 college students attending a major public US university. This 18-34 year old demographic is the heaviest users of the Internet in the population [34] and is commonly used for research concerning online behaviors [35]. Prior to administering the actual survey, we conducted two pilot tests with a total of 37 undergraduate and graduate students. In the first pilot, we checked the validity and reliability of the measurement items. Making some minor wording and order changes to the instrument, we administered the survey in a second round of pilot testing, after which we were satisfied with the instrument, making no changes. We administrated the survey in an undergraduate course, with a response rate of $82.8 \%$. We offered the opportunity to win cash prizes as an incentive to the respondents. 


\subsection{Measurement}

As shown in the Appendix, the survey was composed of three sections. In section one, the participants had to picture themselves in a scenario where they selected a search engine that they would use for a shopping task (i.e., spontaneous awareness), and why. We selected a flower supplier for the task because ecommerce is one of the largest categories of web searches [36], and flower suppliers have less of a branding effect relative to other businesses [37]. We did not want the brand of flower supplies to confound the search engine brand. Chen [37] reports that when branding is less strong in a given task (e.g., flower purchasing), customers tend to search by product category instead of searching for suppliers by brand name (e.g., BMW dealers in the area).

The survey then asked the participants to list their three favorite search engines that they currently use (i.e., top-of-mind awareness). We provide a list of potential reasons to clarify the reasons for choosing a self-selected search engine. The list was composed of items such as dependable, reputation, and trustworthy, which we generated by examining previous literature [38] and generalizing the results of our pilot study. This provided a participant's top search engines and the perceived factors for continued use of these search engines.

In the second portion of the survey, participants were exposed to 10 search engine logos. The logos from nine search engines were taken from actual websites of search engines, and one logo was a fake search engine for our baseline line comparison (i.e., a search engine logo that we were sure no participant had seen before) and validity check of participant responses (i.e., if someone responded they had used this search engine we would have tossed out all responses from that participant). The 10 search engines logos we employed were:

- A9: http://www.a9.com/

- $\mathrm{AI}^{2} \mathrm{RS}$ : fake search engine

- Alltheweb: http://www.alltheweb.com/

- AOL search: http://search.aol.com/aol/webhome 
- Ask.com: http://www.ask.com/

- Dogpile: http://www.dogpile.com/

- Google: www.google.com

- MSN Live search: www.msnlive.com

- Mahalo: http://www.mahalo.com/

- Yahoo!: www.yahoo.com

We used the logos as they exist on the search engine website, without any modification. Many of the logos use the name of the search engine as an integral part of the logo. Therefore, we believed it would artificially alter the logo to remove any brand name mention, even though including the name does, of course, alert the participants to the specific search engine.

Two questions adopted from Henderson and Cote [30] measured meaning consensus and affective impressions of the search engine. Specifically, Please provide the first meaning or association that comes to your mind by looking at the logo? addressed the reaction to the search logo. The second question, What is your overall impression of the search engine? addressed aspects of brand perception of the product itself. The participants were asked whether they had ever used the search engine, and whether they currently use the search engine, which provided us with an indication of the brand awareness and brand marketplace penetration of each. A sample from the survey is shown in Table 1.

\begin{tabular}{|l|l|} 
Please provide the first meaning or association that comes \\
to your mind by looking at the logo. \\
What is your overall impression of the search engine? (For \\
example, like/dislike, good/bad, high/low quality, \\
distinctive/not distinctive, and interesting/uninteresting) \\
Have you used this engine before? (circle) Yes / No \\
If yes, do you currently use this engine? (circle) Yes / No
\end{tabular}

Table 1. Sample Logo and Associated Questions from Survey

The last portion of the survey involved demographic information (gender, age, and ethnicity), as well as background information concerning the students' ability to use search engines. 


\subsection{Data Analysis}

We used a mixed method of quantitative and qualitative approaches, with (as stated) a reliance on the qualitative.

\section{Sentiment Analysis}

To investigate our research questions, we performed a sentiment analysis [39] on the participant comments of the logos and search engines. Specifically, we open coded [40] the responses for positive, negative, and neutral sentiments. Open coding involves examining, conceptualize, parsing, and then classifying verbal data. It is fundamentally interpretive and grounded theory, in that one looks for patterns in the data posterior.

We took a fine grained open coding method, classifying sub-sentence phrases, as participants often contained multiple sentiments within one sentence. Labels for the sentiment responses were defined as follows:

- Positive: Purely positive in tone and wording. May have the smallest negative word, but the comments have almost totally great-sounding phrases. For example, "awesome," "good," and "it's the best."

- Negative: Practically pure negative overall feelings of the comments. For example, "bad," "low quality," and "hard to use."

- Neutral: Has no feeling words or special punctuation, matter-of-fact sounding, or just a mention. For example, "Chemistry," "okay, social search engine," and "never saw before."

\section{Term and Phrase Analysis}

We also performed a linguistic analysis of the participant comments concerning both the logos and the search engine. A term analysis helps define a set of terms that describe a logo's impression or the perception of a search engine in the mind of a set of respondents. We generated a term table and a term co-occurrence table containing all the terms from the entire set of comments. The term table contained 
fields for terms, the number of that term's occurrence in the complete dataset, and the probability of that term's occurrence. The co-occurrence table contains fields for term pairs, the number of times that pair occurs within the data set irrespective of order, from which we calculated the mutual information statistic [41].

The mutual information statistic formula measures the strength of term association and does not assume mutual independence of the terms within the pair. We calculated the mutual information statistic for all term pairs within the data set. Frequently, a relatively low-frequency term pair may be strongly associated (i.e., if the two terms always occur together). The mutual information statistic identifies the strength of this association. The mutual information formula used in this research is as follows:

$$
I\left(\mathrm{w}_{1}, \mathrm{w}_{2}\right)=\ln \frac{\mathrm{P}\left(\mathrm{w}_{1}, \mathrm{w}_{2}\right)}{\mathrm{P}\left(\mathrm{w}_{1}\right) \mathrm{P}\left(\mathrm{w}_{2}\right)}
$$

where $\mathrm{P}(\mathrm{w} 1)$ and $\mathrm{P}(\mathrm{w} 2)$ are probabilities estimated by relative frequencies of the two words and $\mathrm{P}(\mathrm{w} 1$, w2) is the relative frequency of the word pair (order is not considered). Relative frequencies are observed frequencies $(\mathrm{F})$ normalized by the number of the queries:

$$
\mathrm{P}(\mathrm{w} 1)=\frac{\mathrm{F}_{1}}{\mathrm{Q}^{\prime}} ; \mathrm{P}\left(\mathrm{w}_{1}\right)=\frac{\mathrm{F}_{2}}{\mathrm{Q}^{\prime}} ; \mathrm{P}\left(\mathrm{w} 1, \mathrm{w}_{2}\right)=\frac{\mathrm{F}_{12}}{\mathrm{Q}^{\prime}}
$$

Both the frequency of term occurrence and the frequency of term pairs are the occurrence of the term or term pair within the set of queries. However, since a one-term query cannot have a term pair, the set of queries for the frequency base differs. The number of queries for the terms is the number of nonduplicate queries in the data set. The number of queries for term pairs is defined as follows:

$$
Q^{\prime}=\sum_{n}^{m}(2 n-3) Q n
$$


where $\mathrm{Q}_{\mathrm{n}}$ is the number of queries with $\mathrm{n}$ words $(\mathrm{n}>1)$, and $\mathrm{m}$ is the maximum query length. So, queries of length one have no pairs. Queries of length two have one pair. Queries of length three have three possible pairs. Queries of length four have five possible pairs. This continues up to the queries of maximum length in the data set. The formula for queries of term pairs (Q') accounts for this term pairing.

The term and mutual information statistic analysis allowed us a more quantitative manner to evaluate participant comments for sentiment and strength of this sentiment.

\section{RESULTS}

\subsection{Overall Results}

A demographic analysis of the 207 respondents discloses that $54.1 \%$ of the respondents were female. Concerning age, 94.2\% reported an age of 18-24, 5.3\% were 25-32, and one respondent was 47. Regarding racial composition, 77.3\% respondents were White, 15.9 were Asian, 4.3\% Hispanic, and 2.4\% were African American. Of the respondents, 98.4\% claimed high frequency of search engine usage $(\geq 4)$, and $54.1 \%$ reported high frequency of online shopping $(\geq 4)$; only 5 out of 207 rated their search ability as not skilled $(<4)$. So, our sample represents a young, college-age, Internet suave population that generally mirrors the demographics of this age group, although with African-American under represented.

\subsection{Research Question One}

Concerning research question 1 (What are different levels of brand awareness for the various major search engines?), Table 2 shows the results of the brand name that first came to the users' minds when users were asked to identify a search engine to search for an online flower store. 


\begin{tabular}{|l|c|c|}
\hline Search Engine & Occurrences & $\mathbf{\%}$ \\
\hline Google & 195 & 94.2 \\
\hline Yahoo & 10 & 4.8 \\
\hline Ebate & 1 & 0.5 \\
\hline Flowers & 1 & 0.5 \\
\hline Total & 207 & 100 \\
\hline
\end{tabular}

Table 2. Brand awareness Results (top-of-mind)

In Table 2, we see that Google was the first brand recalled in response to the product category cue. Of the participants, $94.2 \%$ prefer Google when they need to search for information. That Google would be the top selection for the majority of searchers would be expected given Google's market dominance at the time of the survey. However, the more than $94 \%$ is really high, as it was reported that Google had less than a $70 \%$ marketshare at the time of the study (comScore, 2009). This may show Google's market dominance at this age group. Yahoo! possesses the second position, but only 10 users $(4.8 \%)$ chose Yahoo! in the experimental scenario.

Some customers went directly to specific websites (e.g., Ebate and Flowers) instead of using a general purpose search engine. This indicates that the phrase 'search engine' is not tightly defined in technological terms by the consumers. The absence of MSN and Ask is surprising, which suggested that they are not the first choice or top tier platforms when users conduct a search. This may be an obstacle in any repositioning or rebranding efforts by these search engines, and it may indicate the effort that Microsoft Bing has had in eroding Google's marketshare since the time of the study.

Table 3 measures different levels of brand awareness but with spontaneous recall as the particular measure.

\begin{tabular}{|c|c|c|c|c|c|c|}
\hline Search Engine & 1st Choice & $\%$ & 2nd Choice & $\%$ & 3rd Choice & $\%$ \\
\hline Google & 197 & 95.2 & 12 & 5.8 & 5 & 2.4 \\
\hline Yahoo & 10 & 4.8 & 118 & 57.0 & 25 & 12.1 \\
\hline blank & & & 22 & 10.6 & 83 & 40.1 \\
\hline Ask & & & 20 & 9.7 & 44 & 21.3 \\
\hline AOL & & & 6 & 2.9 & 12 & 5.8 \\
\hline MSN & & & 8 & 3.9 & 10 & 4.8 \\
\hline Dogpile & & & 4 & 1.9 & 5 & 2.4 \\
\hline Firefox & & & 1 & 0.5 & 4 & 1.9 \\
\hline
\end{tabular}




\begin{tabular}{|c|c|c|c|c|c|c|}
\hline Search Engine & 1st Choice & $\%$ & 2nd Choice & $\%$ & 3rd Choice & $\%$ \\
\hline Wikipedia & & & 2 & 1.0 & 3 & 1.4 \\
\hline AltaVista & & & 1 & 0.5 & 3 & 1.4 \\
\hline Naver & & & 3 & 1.4 & 1 & 0.5 \\
\hline Baidu & & & 3 & 1.4 & & \\
\hline Comcast & & & 2 & 1.0 & 1 & 0.5 \\
\hline Amazon & & & & & 2 & 1.0 \\
\hline $\mathrm{IE}$ & & & 1 & 0.5 & 1 & 0.5 \\
\hline Others & & & 4 & 2.0 & 8 & 4.0 \\
\hline Total & 207 & 100 & 207 & 100 & 207 & 100 \\
\hline
\end{tabular}

Table 3. Brand awareness Results (spontaneous recall)

Note: The highest value in each column is bolded. The following search engines or applications were mentioned only one time: AIM, Alltheweb, Daum, Good Search, Icerocket, Mamma, Safari, Search.com, Sogou, Vivisimo, webmo, and Yamli.com.

In terms of the second favorite search engine, the distribution is more spread out. Yahoo! (57.0\%), Ask $(9.7 \%)$, and Google $(5.8 \%)$ were the three most popular search engines in this category. It is interesting to note that, among these 12 users who chose Google, 10 listed Yahoo! as their first choice, which indicated the competitive relationship between these two brands. (There were two participants who listed Google as their second choice also.) Most important, all the respondents (save the two who listed Google twice) had a second place search engines. This indicates that there may be an opening for a market entry, as it may indicate there are search needs not being satisfactorily fulfilled by a participant's first choice search engine. An interesting follow-on study would be to see how often participants leverage these second choice search engines and for what type of searches.

Regarding the third favorite search engine, most participants left it blank (40.1, indicating that consumers voluntarily limit their search options. Some users switch to a different search engine when they cannot complete their task by using the one they first selected, but most users revealed that they will give up after searching on their first choice, with comments like, for example, "things [that] cannot be found on Google cannot be found anywhere." Some foreign brands, such as Baidu (Chinese), Naver (Korean), and Yamli (Arabic) were mentioned. This is likely due to the different ethnic backgrounds of the research participants. 
The results in Tables 2 and 3 clearly demonstrate the impact of brand awareness on search engine users' perceptions. For example, Google, which possesses the largest market share at the time of the survey, was ranked as the favorite search engine brand when users were asked to recall those search engine brands, and consistently, $94.2 \%$ of users identified Google as the search engine they used for information ecommerce searching. This suggests that users tend to choose the brand that they are most aware of, can recall more easily, and are more familiar with for performing a searching task. This makes it more difficult for general purpose search engines to successfully enter the marketplace by overcoming consumer habit with a product that meets their needs.

When presenting the 10 search engine logos to each participant, we also asked whether the participants had used the search engine before (Table 4) and whether they currently used the search engine (Table 5).

\begin{tabular}{|c|c|c|c|c|c|}
\hline & \multicolumn{4}{|c|}{ Used Before } & \multirow[b]{2}{*}{ Total } \\
\hline Search Engine & Yes & $\%$ & No & $\%$ & \\
\hline Google & 199 & $96.1 \%$ & 8 & $3.9 \%$ & 207 \\
\hline Yahoo! & 188 & $90.8 \%$ & 19 & $9.2 \%$ & 207 \\
\hline Ask & 168 & $81.2 \%$ & 39 & $18.8 \%$ & 207 \\
\hline $\mathrm{AOL}$ & 133 & $64.3 \%$ & 74 & $35.7 \%$ & 207 \\
\hline Dogpile & 62 & $30.0 \%$ & 145 & $70.0 \%$ & 207 \\
\hline MSN Live & 54 & $26.1 \%$ & 153 & $73.9 \%$ & 207 \\
\hline Alltheweb & 6 & $2.9 \%$ & 201 & $97.1 \%$ & 207 \\
\hline Mahalo & 4 & $1.9 \%$ & 203 & $98.1 \%$ & 207 \\
\hline A9 & 2 & $1.0 \%$ & 205 & $99.0 \%$ & 207 \\
\hline $\mathrm{AI}^{2} \mathrm{RS}$ & 0 & $0.0 \%$ & 207 & $100.0 \%$ & 207 \\
\hline
\end{tabular}

Table 4. Participants' prior use of the search engine

Note: The highest value in each column is bolded.

\begin{tabular}{|c|c|c|c|c|c|}
\hline & \multicolumn{4}{|c|}{ Currently Use } & \multirow[b]{2}{*}{ Total } \\
\hline Search Engine & Yes & $\%$ & No & $\%$ & \\
\hline Google & 197 & $95.2 \%$ & 10 & $4.8 \%$ & 207 \\
\hline Yahoo! & 116 & $56.0 \%$ & 91 & $44.0 \%$ & 207 \\
\hline Ask & 50 & $24.2 \%$ & 157 & $75.8 \%$ & 207 \\
\hline $\mathrm{AOL}$ & 22 & $10.6 \%$ & 185 & $89.4 \%$ & 207 \\
\hline Dogpile & 14 & $6.8 \%$ & 193 & $93.2 \%$ & 207 \\
\hline MSN Live & 8 & $3.9 \%$ & 199 & $96.1 \%$ & 207 \\
\hline
\end{tabular}




\begin{tabular}{|l|r|r|r|r|r|}
\hline & \multicolumn{6}{|c|}{ Currently Use } & \\
\hline \multicolumn{1}{|c|}{ Search Engine } & \multicolumn{1}{|c|}{ Yes } & \% & No & \% & \multicolumn{1}{c|}{ Total } \\
\hline Mahalo & 2 & $1.0 \%$ & 205 & $99.0 \%$ & 207 \\
\hline $\mathrm{A} 9$ & 0 & $0.0 \%$ & $\mathbf{2 0 7}$ & $\mathbf{1 0 0 . 0} \%$ & 207 \\
\hline $\mathrm{AI}^{2} \mathrm{RS}$ & 0 & $0.0 \%$ & $\mathbf{2 0 7}$ & $\mathbf{1 0 0 . 0 \%}$ & 207 \\
\hline Alltheweb & 0 & $0.0 \%$ & $\mathbf{2 0 7}$ & $\mathbf{1 0 0 . 0} \%$ & 207 \\
\hline
\end{tabular}

Table 5. Participants currently using the search engine

Note: The highest value in each column is bolded.

In Table 4, we see two groupings emerge. One group is the search engines that had very little brand usage from the participants (A9, $\mathrm{AI}^{2} \mathrm{RS}$, Alltheweb, and Mahalo). The other group are the search engines with high percentages of brand usage (AOL, ASK, Dogpile, Google, MSN Live, and Yahoo!). Our validity check search engine $\left(\mathrm{AI}^{2} \mathrm{RS}\right)$ was in the never have used category, along with the smaller and much less known search engines. So, there were no surprises here.

In the elevated brand group, there are two tiers, a very high usage tier (AOL, Ask, Google, and Yahoo!) and a second tier of lesser usage (Dogpile and MSN Live). The mention of Dogpile in this group may be expected; however, the inclusion of MSN Live in the second tier is somewhat surprising, as it has substantial financial backing from a major technology company.

The high prior usage of Yahoo!, Ask, and AOL reflected previous marketshare, when these search engine companies possessed higher portions of the market than at the time of the study. This is reflected in comments concerning Yahoo!, such as "before Google". However, the demographic characteristics of our study participants may bring some bias. Yahoo! may have had a higher position if more middle-aged participants had been recruited in the study. This is an area for future research.

It is interesting to compare what users have tried to what they are currently using. The comparison of prior (Table 4) and current usage (Table 5) shows the change in market share in the search engine industry. We see Google maintaining a consistent market share (i.e., nearly the same percentage of users who tried Google and are currently using Google), while all other search engine usage drops, 
notably from AOL, Ask, MSN Live, and Yahoo!. The decrease in the number of users of Dogpile and MSN Live is significant, which is $23.2 \%$ and $22.2 \%$. The decreasing trend also holds true for Alltheweb and A9, but is not significantly. Furthermore, it deserves to be noted that the percentage of participants who reported currently using Ask (24\%) and Yahoo! (56\%) is quite high, much higher than reported search market share [42]. This would possible indicate an occasional usage when their primary search engine did not perform well.

We originally wanted to conducted stratified analysis of the participants impressions of the search engine logos based on usage by search engine. However, the number of participants for most search engines (other than Google) was too low for any meaningful analysis.

\section{3. $\quad$ Research Question Two}

For research question 2 (Do different search engine logos cause different brand responses?), the results from our sentiment analysis are shown in Table 6 . A cross tab analysis $(\chi(60)=2730.605, \mathrm{p}<0.01)$ clearly shows that there were different brand responses from the participants concerning the search logos, with three apparent groupings of logos. 


\begin{tabular}{|c|c|c|c|c|c|c|c|c|c|c|c|}
\hline Logo & Positive & $\%$ & Negative & $\%$ & Neutral & $\%$ & Confusing & $\%$ & No response & $\%$ & Total \\
\hline Google & 131 & $63.3 \%$ & 1 & $0.5 \%$ & 28 & $13.5 \%$ & 1 & $0.5 \%$ & 46 & $22.2 \%$ & 207 \\
\hline Yahoo! & 79 & $38.2 \%$ & 17 & $8.2 \%$ & 53 & $25.6 \%$ & 1 & $0.5 \%$ & 57 & $27.5 \%$ & 207 \\
\hline Ask & 55 & $26.6 \%$ & 15 & $7.2 \%$ & 81 & $39.1 \%$ & 0 & $0.0 \%$ & 56 & $27.1 \%$ & 207 \\
\hline Alltheweb & 53 & $25.6 \%$ & 51 & $24.6 \%$ & 35 & $16.9 \%$ & 4 & $1.9 \%$ & 64 & $30.9 \%$ & 207 \\
\hline Dogpile & 39 & $18.8 \%$ & 55 & $26.6 \%$ & 48 & $23.2 \%$ & 4 & $1.9 \%$ & 61 & $29.5 \%$ & 207 \\
\hline AOL & 30 & $14.5 \%$ & 29 & $14.0 \%$ & 89 & $43.0 \%$ & 0 & $0.0 \%$ & 59 & $28.5 \%$ & 207 \\
\hline A9 & 22 & $10.6 \%$ & 16 & $7.7 \%$ & 64 & $30.9 \%$ & 20 & $9.7 \%$ & 85 & $41.1 \%$ & 207 \\
\hline Mahalo & 21 & $10.1 \%$ & 21 & $10.1 \%$ & 83 & $40.1 \%$ & 7 & $3.4 \%$ & 75 & $36.2 \%$ & 207 \\
\hline MSN Live & 18 & $8.7 \%$ & 32 & $15.5 \%$ & 81 & $39.1 \%$ & 2 & $1.0 \%$ & 74 & $35.7 \%$ & 207 \\
\hline $\mathrm{AI}^{2} \mathrm{RS}$ & 9 & $4.3 \%$ & 96 & $46.4 \%$ & 33 & $15.9 \%$ & 8 & $3.9 \%$ & 61 & $29.5 \%$ & 207 \\
\hline Total & 456 & $22.0 \%$ & 333 & $16.1 \%$ & 595 & $28.7 \%$ & 47 & $2.3 \%$ & 638 & $30.8 \%$ & 2070 \\
\hline
\end{tabular}

Table 6. Sentiment analysis of search engine logos

Note: The highest value in each column is bolded. 
In one group, several search engine logos elicited positive sentiment, including Google (63\%), Yahoo! (38\%), and Ask (27\%). These three logos elicited mainly positive sentiment with little negative reaction. These three logos have intrinsic and extrinsic attributes in common. Their logos are all colorful and primarily contain just the text of the search engine name (intrinsic) y are all well known in the search engine market (extrinsic).

This is in contrast to logos in the second group that elicited considerable negative sentiment, including $\mathrm{AI}^{2} \mathrm{RS}(46 \%)$ and Dogpile (27\%). The logo with the most negative sentiment by far was the $\mathrm{AI}^{2} \mathrm{RS} \operatorname{logo}$, which many participants associated with math or science due to the superscript included in the logo and the lack of market awareness, which was zero. We believed that the zero recognition of this logo, as the baseline, helps showed the validity of the responses overall.

Dogpile also received a significantly negative reaction due to its close similarity to a phrase meaning canine feces, with comments such as "bad name because gives the idea the answers are shitty." In addition to the search engine name, the logo also contains a paw print, perhaps reinforcing the canine association. Alltheweb negative comments were due to its logo design, which, according to users' comments, is too cluttered. As you can see, the Alltheweb logo has artistic rendering of some lettering, a tag line, and some multi-colored bubbles, which is noticeably different than most of the other search engine logos.

The third group was mixed responses. The logo for A9 was confusing to many respondents, who said the logo reminded them of AOL (A9 is a search engine owned by Amazon.com.) or a dog (perhaps referring to canine).

It is worthwhile to note that this ranking of grouped sentiment responses to brand logos (from positive to negative) reflects the general marketplace groupings of the search engines. As well-known search engine brands, Google, Yahoo!, and Ask evoked the most positive sentiment; meanwhile, they 
are the three of the biggest market share holders the time of the study. This in line with prior research showing that the brand of major search engines results in a boost in performance evaluation [3]. Conversely, less-well-known search engines where primarily negatively perceived. Mahalo, A9, and $\mathrm{AI}^{2} \mathrm{RS}$ (fictitious), share a small (to zero) portion of the market in reality. So, it would appear that extrinsic properties are playing a part in the affective responses of the respondents.

Again, the exception is MSN Live. MSN Live had substantial marketshare but numerous negative comments. It is unusually to see as a well known search engine at such a low ranking. This may hint at a problem existing in the brand name or logo design of MSN Live. Also, this indicates that MSN's move to rebrand the search engine to Bing (MSN Live changed its name to Bing on May 28, 2009) was probably a good move in terms of marketing.

We conducted a phrase analysis using term pairs, with the top phrases presented in Table 7. 


\begin{tabular}{|c|c|c|c|c|c|c|c|c|c|c|c|}
\hline \multicolumn{3}{|c|}{ A9 } & \multicolumn{3}{|c|}{$\mathbf{A I}^{2} \mathbf{R S}$} & \multicolumn{3}{|c|}{ Alltheweb } & \multicolumn{3}{|c|}{ AOL } \\
\hline Phrase & $\mathrm{F}$ & MIS & Phrase & $\mathrm{F}$ & MIS & Phrase & $\mathrm{F}$ & MIS & Phrase & $\mathrm{F}$ & MIS \\
\hline search engine & 9 & 3.35 & search engine & 5 & 3.90 & search engine & 8 & 3.02 & search engine & 10 & 2.58 \\
\hline never heard & 8 & 3.29 & don't know & 5 & 3.90 & find it & 5 & 1.80 & aol search & 4 & 0.08 \\
\hline no idea & 10 & 3.66 & never heard & 3 & 3.61 & everything find & 4 & 3.01 & not good & 3 & 3.28 \\
\hline \multicolumn{3}{|c|}{ Dogpile } & \multicolumn{3}{|c|}{ Google } & \multicolumn{3}{|c|}{ Mahalo } & \multicolumn{3}{|c|}{ MSN Live } \\
\hline Phrase & $\mathrm{F}$ & MIS & Phrase & $\mathrm{F}$ & MIS & Phrase & $\mathrm{F}$ & MIS & Phrase & $\mathrm{F}$ & MIS \\
\hline search engine & 8 & 3.32 & search engine & 15 & 2.70 & never heard & 6 & 3.05 & search engine & 7 & 2.89 \\
\hline dog shit & 3 & 2.28 & best search & 3 & 1.93 & never seen & 3 & 3.21 & don't use & 3 & 4.44 \\
\hline middle school & 3 & 4.52 & easy use & 3 & 3.31 & hawaii hello & 2 & 1.76 & don't know & 2 & 4.44 \\
\hline \multicolumn{3}{|c|}{ Ask } & \multicolumn{3}{|c|}{ Yahoo! } & & & & & & \\
\hline Phrase & $\mathrm{F}$ & MIS & Phrase & $\mathrm{F}$ & MIS & & & & & & \\
\hline ask jeeves & 17 & 1.49 & search engine & 10 & 3.01 & & & & & & \\
\hline ask question & 8 & 1.14 & my favorite & 2 & 3.57 & & & & & & \\
\hline question you & 7 & 2.51 & yahoo like & 2 & 1.78 & & & & & & \\
\hline
\end{tabular}

Table 7. Phrase analysis of search engine logos comments

Note: MIS - mutual information statistic 
The phrase and frequency are shown as well as the mutual information statistic, which shows the strength of the term relationship (the higher the better). Table 7 shows some interesting associations with some of these logos. We see that the Google logo elicited some extremely positive responses. Yahoo! also has many positive statements associated with its logo, although there were several comments relating to the Yahoo! television commercial rather than the search engine. This may indicate an issue with the advertising message and brand image that the Yahoo! company is portraying.

There were several logos where there were associated relationships rather than web searching. For example, math was linked with $\mathrm{AI}^{2} \mathrm{RS}$, questions associated with Ask, dogs with Dogpile, and Hawaii connected with Mahalo. It indicates that the intrinsic aspects of a search engine logo can raise not only positive effects but also confounding properties. Specifically, the attributes of these particular search engines were not providing a coherent message to recipients.

There were other confounding issues with some logos. The A9 logo provided no contextual clue for many participants (e.g., participant responses included no idea, no clue, etc.), as did the $\mathrm{AI}^{2} \mathrm{RS}$ logo. The Ask logo was not only routinely associated with question asking but also with the company's previous brand, Ask Jeeves. Dogpile was not only associated with a dog search engine but also a surprising number of dog feces subjects, and Mahalo was routinely related to a search engine for Hawaiian information or Hawaiian travel. Obviously, these are not the brand images that these companies want associated with their logos, indicating issues with their lack of consistent marketing messages.

Similarly, there were some cross-brand associations, where the search service was associated with some other product from the brand. Participants associated the AOL logo with AIM and the MSN Live logo with Windows. It would imply that these search engines do not have a firmly planted brand image as search engines in the minds of the participants. 
Practice dictates that well-designed logos should elicit consensually held meanings and evoke a positive effect $[43,29]$. Keller [6] argued that marketing stimuli should communicate one clear message that is difficult to misinterpret. As one of the most important visual stimuli, a logo should be able to deliver a clear and consensual meaning to the users. In this regard, an appropriately designed logo can bring benefits to the company. Therefore, these search engine companies with associated or confounding messages should consider redesigning logos if the meanings desired are different from consumers' perceptions, which is apparent with some of these search engine companies.

\subsection{Research Question Three}

For research question 3 (What are the different search engines brand perceptions?), the results from our sentiment analysis for the various search engines are shown in Table 8.

\begin{tabular}{|l|r|c|r|r|r|r|r|r|r|r|r|}
\hline $\begin{array}{l}\text { Search } \\
\text { Engine }\end{array}$ & Positive & $\mathbf{\%}$ & Negative & $\mathbf{\%}$ & Mixed & $\mathbf{\%}$ & Neutral & $\mathbf{\%}$ & $\begin{array}{c}\text { No } \\
\text { Response }\end{array}$ & \% & Total \\
\hline Google & $\mathbf{1 8 0}$ & $\mathbf{8 7 . 0 \%}$ & 1 & $0.5 \%$ & & $0.0 \%$ & & $0.0 \%$ & 26 & $12.6 \%$ & 207 \\
\hline Yahoo! & 123 & $59.4 \%$ & 12 & $5.8 \%$ & $\mathbf{3 3}$ & $\mathbf{1 5 . 9 \%}$ & & $0.0 \%$ & 39 & $18.8 \%$ & 207 \\
\hline Ask & 109 & $52.7 \%$ & 31 & $15.0 \%$ & 24 & $11.6 \%$ & 4 & $1.9 \%$ & 39 & $18.8 \%$ & 207 \\
\hline AOL & 81 & $39.1 \%$ & 44 & $21.3 \%$ & 25 & $12.1 \%$ & 5 & $2.4 \%$ & 52 & $25.1 \%$ & 207 \\
\hline Total & 788 & $38.1 \%$ & 438 & $21.2 \%$ & 153 & $7.4 \%$ & 118 & $5.7 \%$ & 573 & $27.7 \%$ & 207 \\
\hline Dogpile & 75 & $36.2 \%$ & 38 & $18.4 \%$ & 17 & $8.2 \%$ & 9 & $4.3 \%$ & 68 & $32.9 \%$ & 207 \\
\hline Mahalo & 66 & $31.9 \%$ & 32 & $15.5 \%$ & 16 & $7.7 \%$ & 16 & $7.7 \%$ & 77 & $37.2 \%$ & 207 \\
\hline Alltheweb & 54 & $26.1 \%$ & 68 & $32.9 \%$ & 7 & $3.4 \%$ & 18 & $8.7 \%$ & 60 & $29.0 \%$ & 207 \\
\hline MSN Live & 46 & $22.2 \%$ & 56 & $27.1 \%$ & 14 & $6.8 \%$ & 13 & $6.3 \%$ & 78 & $37.7 \%$ & 207 \\
\hline A9 & 30 & $14.5 \%$ & 63 & $30.4 \%$ & 8 & $3.9 \%$ & $\mathbf{2 7}$ & $\mathbf{1 3 . 0 \%}$ & 79 & $38.2 \%$ & 207 \\
\hline AI ${ }^{2}$ RS & 24 & $11.6 \%$ & $\mathbf{9 3}$ & $\mathbf{4 4 . 9 \%}$ & 9 & $4.3 \%$ & 26 & $12.6 \%$ & 55 & $26.6 \%$ & 207 \\
\hline
\end{tabular}

Table 8. Sentiment analysis of search engine comments

Note: The highest value in each column is bolded.

A cross tab analysis $(\chi(50)=2681.02, \mathrm{p}<0.01)$ shows that there are different brand responses to the search engines. In terms of brand perception of the search engines, we see that Google has far and away the highest positive brand perception (87\%), which is much higher than its marketshare at the time of the study. Additionally, the depth of the positive sentiment is amazing, with comments such as "Ahh, love sweet home". The term love was used by several participants to describe Google. 
It is obvious the brand "Google" conveys a clear and strong meaning to users with zero percent mixed or neutral responses. This may be due to Google's brand equity associations as a whole, including high awareness, positive image, and well-established relationship with customers. However, the depth and range of positive affective sentiment was still surprising. It indicates the difficult of other search engines being able to dislodge Google as the brand image market leader.

Other search engines with positive sentiment are Yahoo! (59\%) and Ask (53\%), so these search engines also have healthy positive brand perception.

In between, some popular search engine brands (e.g., Ask, AOL, and Yahoo!) possess high mixed responses. This may due to their vague market positioning strategy and lack of characteristics that differentiates them from other companies and searching products. Yahoo!'s mixed sentiment was generally along the line of a good search engine but not as good as Google (e.g., "what came before google" and "used to use it until I met google"). Mahalo had some mixed comments, such as "Internet 2.0, trendy, short-lived”. Less-well-known brands, such as Dogpile, Mahalo, and Alltheweb, have almost equally distributed positive and negative responses with fewer mixed and neutral responses.

We conducted a phrase analysis of two terms, with the three most frequent phrases presented in Table 9. The phrase and frequency are shown as well as the mutual information statistic that shows the strength of the term relationship (the higher the better). For this aspect, we asked users their overall impression of the search engine, which is expected to be slightly different from their first meaning or association by just referring to the logos. However, from the phrase analysis, three search engines stand out on the positive side, Ask, Google, and Yahoo!, with nearly all positive phrases. 


\begin{tabular}{|c|c|c|c|c|c|c|c|c|c|c|c|}
\hline \multicolumn{3}{|c|}{ A9 } & \multicolumn{3}{|c|}{$\mathrm{AI}^{2} \mathrm{RS}$} & \multicolumn{3}{|c|}{ Alltheweb } & \multicolumn{3}{|c|}{ AOL } \\
\hline Phrase & $\mathrm{F}$ & MIS & Phrase & $\mathrm{F}$ & MIS & Phrase & $\mathrm{F}$ & MIS & Phrase & $\mathrm{F}$ & $\mathrm{MIS}$ \\
\hline $\begin{array}{l}\text { not } \\
\text { distinctive }\end{array}$ & 12 & 2.66 & $\begin{array}{l}\text { not } \\
\text { distinctive }\end{array}$ & 10 & 2.28 & $\begin{array}{l}\text { not } \\
\text { distinctive }\end{array}$ & 11 & 2.83 & like good & 14 & 1.25 \\
\hline low quality & 7 & 2.58 & $\begin{array}{l}\text { dislike } \\
\text { uninteresting }\end{array}$ & 9 & 1.04 & low qual & 11 & 2.62 & like high & 11 & 1.99 \\
\hline low qual & 6 & 2.79 & don't know & 8 & 3.15 & low quality & 10 & 2.68 & $\begin{array}{l}\text { not } \\
\text { distinctive }\end{array}$ & 11 & 1.87 \\
\hline \multicolumn{3}{|c|}{ Dogpile } & \multicolumn{3}{|c|}{ Google } & \multicolumn{3}{|c|}{ Mahalo } & \multicolumn{3}{|c|}{ MSN Live } \\
\hline Phrase & $\mathrm{F}$ & MIS & Phrase & $\mathrm{F}$ & MIS & Phrase & $\mathrm{F}$ & MIS & Phrase & $\mathrm{F}$ & MIS \\
\hline $\begin{array}{l}\text { like } \\
\text { distinctive }\end{array}$ & 8 & 1.24 & high qual & 41 & 2.28 & $\begin{array}{l}\text { not } \\
\text { distinctive }\end{array}$ & 7 & 1.87 & $\begin{array}{l}\text { not } \\
\text { distinctive }\end{array}$ & 7 & 2.51 \\
\hline $\begin{array}{l}\text { not } \\
\text { distinctive }\end{array}$ & 7 & 2.24 & like good & 39 & 1.63 & $\begin{array}{l}\text { distinctive } \\
\text { interesting }\end{array}$ & 6 & 0.85 & dislike low & 6 & 2.42 \\
\hline $\begin{array}{l}\text { like } \\
\text { interesting }\end{array}$ & 7 & 1.11 & like high & 33 & 1.41 & like good & 6 & 1.84 & dislike bad & 6 & 1.93 \\
\hline \multicolumn{3}{|c|}{ Ask } & \multicolumn{3}{|c|}{ Yahoo! } & & & & & & \\
\hline Phrase & $\mathrm{F}$ & MIS & Phrase & $\mathrm{F}$ & MIS & & & & & & \\
\hline like good & 15 & 0.70 & like good & 18 & 0.98 & & & & & & \\
\hline like high & 10 & 1.34 & high qual & 11 & 2.81 & & & & & & \\
\hline $\begin{array}{l}\text { like } \\
\text { distinctive }\end{array}$ & 10 & 1.23 & $\begin{array}{l}\text { like } \\
\text { interesting }\end{array}$ & 10 & 1.88 & & & & & & \\
\hline
\end{tabular}

Table 9 Phrase analysis of search engine comments

Note: MIS - mutual information statistic

On the affirmative side, we see that Google elicited a string of positive comments from the participants. In fact, 22 participants actually used the term 'love' in their responses, again an usually emotional sentiment for a brand. AOL, Ask, and Yahoo! also have many positive phrases, although there was some negative phrase usage also for these search engines. Most of the other search engines had primarily negative terms associated with them.

On the negative side, $\mathrm{A} 9, \mathrm{AI}^{2} \mathrm{RS}$, and MSN Live all had overwhelmingly negative phrase sentiment. For example, comments about MSN Live were 'boring' and 'dislike, bad, low, indistinctive, uninteresting'.

These findings suggests that part of users' responses to search engines is based on users' reactions just to the logos, especially for brands that are unfamiliar, since they probably base their responses on intrinsic attributes. For the search engines that are familiar, it also suggests the linkage between 
perceptions of performance and emotional projection to the brands logo, with some reliance on extrinsic attributes. The implication is that, for new entries to the marketplace, a good logo can be a competitive advantage.

Interestingly, there was not always a correlation between the brand response to the logo and whether or not a participant had used, not used or was currently using the search engine. For example, A9 and Mahalo had very little brand recognition but also relatively low negative logo brand responses, which indicated that logos can evoke a negative effect without being recognized as search engines. In contrast, MSN Live and AOL had high brand recognition and relatively low negative brand logo responses. The bottom line for search engines, both established and emerging, is that logo design can have an effect on potential consumer perception of the overall brand, especially in invoking negative responses.

\section{DISCUSION AND IMPLICATIONS}

Both quantitative and qualitative research methods were adopted to address important branding issues in the search engine area. This research has both implications for academic researchers and managerial implications for industry practitioners at both established search engines and search engine start-ups. It is apparent that the logo of a search engine company is symbolic in the consumers mind for a variety of referential proprieties, attributes, and associations, both cognitively and affectively and intrinsically and extrinsically. Findings indicate that clear brand identity as expressed in a search engine's logo is important for recognition and familiarity of the brand. Also, the logo characteristics featured must be aligned with the overall brand objective to ensure consistent messaging.

Our examination of 10 search engine logos and users' responses clearly suggests that a search engine brand, as represented by the logo, can have a significant effect on how potential customers perceive the search engine. Many of the logos in our survey (e.g., $\mathrm{AI}^{2} \mathrm{RS}$, Ask, Dogpile, and Mahalo) induced 
incorrect perceptions of the search engine. $\mathrm{AI}^{2} \mathrm{RS}$ was perceived as being for math or science searches, Ask was only for questions, Dogpile was a dog search service, and Mahalo was a Hawaiian search service. In general, a brand logo should convey a clear and consistent message for a lucid brand image.

Two major reasons for failure are identified. First, some logos failed to evoke a positive effect, such as Dogpile and $\mathrm{AI}^{2} \mathrm{RS}$. There were inherent elements of the logo that evoked other responses in the participants (e.g., dogs for Dogpile and math for $\mathrm{AI}^{2} \mathrm{RS}$ ). Second, some logos failed to elicit a consensual meaning (e.g., Ask and Mahalo that had positive and negative sentiments), with associated relationship messages. The creation of positive effective reactions is critical to a logo's success because the effect can transfer from the logo to the product or company. The evaluation of the quality of the product will be influenced by the evaluation of logos, even the initial impression of the logo design.

The message delivered by the logos should be the meaning that brand intended, and the message must be clear. There is a danger in these mixed logo messages for search engines, especially when the service does not attract the correct audience or does not live up to the customer's expectation. For example, many participants expect Ask to respond to questions. So, when it does not, it creates a negative brand perception, such as "doesn't give the answers, bad experiences, dislike, and bad and low quality."

We can extrapolate to other search engines. For example, Bing was being branded shortly after the time of this study as a 'decision engine', which may set-up potential searchers for an unachievable performance expectation when it does not 'make decisions'. Therefore, designing and selecting a logo for their search company or product must be a careful process, with adequate marketing research. As Mitta [44] has discussed, one can view a brand as an extension of ones self, so it would seem that people would associate with brands that create positive perceptions of self. 
Concerning the usage of the search engines, it is clear that breaking into search engine marketing or gaining a significant positive brand perception is not an easy task. The search engines with the most positive image were typically the ones with already high rates of usage and relative early entry into the market (AOL, Ask, Google, and Yahoo!). The late entries into the market, A9, Mahalo, and the fake search engine, $\mathrm{AI}^{2} \mathrm{RS}$, suffer from negative brand perception. This is interesting, as the search engine market has extremely low switching cost. It may be, given the gushing sentiment expressed by participants over Google, that searchers develop an emotional bond with the search engine, making it affectively difficult to for the searcher to switch to another engine.

Especially with Google, there is also the bandwagon effect [45]. Google has become the generic term for web search. Prior research has shown that popularity with search engines is a major factor in determining use [38]. With the cumulative effect of prior branding, those market leaders, such as Google and Yahoo!, are familiar and popular among student groups. Participants responded with comments such as "all my friends are using it." Also, Hoffman [46] notes that a logo may not only represent the brand but also the consumers image of themselves. It is difficult for new search engine brands to establish themselves as market leaders in this situation, considering how hard it is to compete with these influential services in almost every brand equity association. So, in addition to cognitive responses of search engine performance, the logo can elicit affective responses and be a visual cue for the recall of previous experiences. Under these circumstances, the search engines' marketing strategy is more critical than ever. This research provides insights in assisting companies in this effort, for example, conveying a positive and correct brand image by designing logos appropriately

However, some established search engines, MSN Live, Alltheweb, and Dogpile, also had mixed brand perceptions. Several reasons might provide insight into why this is so. Perhaps these search engines were tried, but they did not live up to the performance expectations of the searchers. However, a more likely explanation is, again, the bandwagon effect. Prior research has shown that the performance 
of most web search engines is similar [2]. However, when a particular search engine become popular (i.e., Google), a searcher may feel compelled to switch to the more popular search engine. This is another example of the bandwagon effect (perhaps it should be called the brandwagon effect). The users then justify their decision for leaving the prior search engine with negative sentiment.

Yahoo! is also an interesting case, with a lot of positive sentiment, but the Yahoo! logo also generated much "also ran" comments, relative to Google. As Yahoo! works to rebrand itself, at the time of this study, from a direct search service to more of a content provider, perhaps a reworking of the Yahoo! logo may be in order to synergize with the new strategy. Clow and Baack [16] note that slightly altering a logo has positive reaction from potential consumers, while still retaining some of the prior logo branding. This consumer behavior is explained by social judgment theory [47], where incremental change is palatable for consumers.

Finally, there seems to be a positive correlation between search engine perception and search engine usage, generally. Assuming that the search engine performance is in general the same or better in response to user searches relative to other search engines, it would indicate that if a search engine can get a customer to use its service for a period of time, the response may be positive brand perception and, therefore, continued usage either as a primary or secondary search service. However, how to get the extended trial is always a problem for marketing managers. Search engine companies can increase their attraction through developing creative functions for searching, taking advantage of the branding effect, and via third party agreements.

The limitations of the study concern the sample and presentation of the logos. The sample was a convenience sample of college undergraduates, which might not be representative of the entire web population. This is especially an issue in terms of the age, as younger and older web searchers may have other brand perceptions of the search engines. However, students have been used as surrogates for 
general web users in this important age group. Additionally, there is increasing questions whether or not demographic factors like age, gender or race are significant factors in ecommerce [22,48]. Therefore, we believe our findings to be generalizabilty to the larger web population for this age bracket. However, we acknowledge that a randomized experiment involving a larger and more diverse sample of the web population would be beneficial. Another possible limitation is that many of the logos contained text of the search engine name, which may have confounded the participants' responses. However, we believe removing the text would have created a too artificial environment, which would not represent the real world context.

There are several strengths of the study, including the large number of participants, the extensive pilot testing of the instrument, and the analysis from multiple perspectives. The age range of the participants is also a critical demographic for Internet marketers. Therefore, we believe our findings provide important and interesting insights into this branding aspect of search engine logos.

\section{CONCLUSION}

It is obvious that search engine companies should be careful about the design of their logos. Logos are an important component of web search engine interfaces, given that these search interfaces are usually very simple, and search engine logos can cause both positive and negative brand image responses. Poor design of logos can directly lead to negative impressions of search engine quality, especially among potential customers who have little brand awareness. Brand awareness, was also demonstrated to have different levels of impact on users' perceptions of major search engine brands. This study provides some knowledge concerning branding implications in the search engine industry. Future research can broaden the results by taking different customer types into consideration and rethinking the strategy and process of brand relationship building. 


\section{REFERENCES}

1. Orman, L. V. (2008). Browsing databases with constraint hierarchies. Electronic Commerce Research, 8(1-2), 29-56.

2. Eastman, C. M., \& Jansen, B. J. (2003). Coverage, ranking, and relevance: A study of the impact of query operators on search engine results. ACM transactions on information systems, 21(4), 383411.

3. Jansen, B. J., Zhang, M., \& Schultz, C. D. (2009). Search engine brand and the effect on user perception of searching performance. Journal of the american society for information science and technology.

4. Keller, K. L., \& Lehmann, D. R. (2006). Brands and branding: Research findings and future priorities. Marketing science, 25(6), 740-759.

5. Haigh, D., \& Knowles, J. (2004). How to define your brand and determine its value. Marketing Management, 13(3), 22-28.

6. Keller, K. L. (1993). Conceptualizing, measuring, and managing customer-based brand equity. Journal of marketing, 51(1), 1-22.

7. Percy, L., \& Rossiter, J. R. (1992). A model of brand awareness and brand attitude adverting strategies. Psychology and Marketing (1996-1998), 9(4), 263-274.

8. Rubel, E. A. (1994). Trademarks and the press: A year in review. Editor \& Publisher, 127, 6T-26T.

9. Kohli, C., Suri, R., \& Thakor, M. (2002). Creating effective logos: Insights from theory and practice. Business Horizons(May-June), 58-64.

10. Robinson, T. N., Borzekowski, D. L. G., Matheson, D. M., \& Kraemer, H. C. (2007). Effects of fast food branding on young children's taste preferences. Archives of Pediatrics \& Adolescent Medicine, 161(1), 792-797.

11. Perrachione, T. K., \& Perrachione, J. R. (2008). Brains and brands: Developing mutually informative research in neuroscience and marketing. Journal of consumer behaviour, 7(4-5), 303 $-318$.

12. Selame, E., \& Selame, J. (1988). The company image: Building your identity and influence in the marketplace. New York: Wiley.

13. Chevalier, M., \& Mazzalovo, G. (2004). Pro logo: Brands as a factor of progress. London: Palgrave Macmillan.

14. Buttle, H., \& Westoby, N. (2006). Brand logo and name association: It's all in the name. Applied Cognitive Psychology, 20(9), 1181-1194.

15. Van den Bosch, A. L. M., de Jong, M. D. T., \& Elving, W. J. L. (2005). How corporate visual identity supports reputation. Corporate Communications: An International Journal, 10(2), 108116.

16. Clow, K. E., \& Baack, D. (2007). Integrated advertising, promotion, and marketing communications. Upper Saddle River, New Jersey: Pearson International.

17. Pittard, N., Ewing, M., \& Jevons, C. (2007). Aesthetic theory and logo design: Examining consumer response to proportion across cultures. International Marketing Review, 24(4), 457-473.

18. Spiekermann, S., \& Paraschiv, C. (2002). Motivating human-agent interaction: Transferring insights from behavioral marketing to interface design. Electronic Commerce Research, 2(3), 255-285.

19. Davies, J. (1996). How does corporate identity work? Campaign, 27(September), 36-37.

20. Check-Teck, F. (2001). Designing e-logos in corporate identity strategy. Brand Management, 8(4\&5), 334-345. 
21. Goel, L., \& Prokopec, S. (2009). If you build it will they come?-an empirical investigation of consumer perceptions and strategy in virtual worlds. Electronic Commerce Research, 9(1-2), $115-134$.

22. Lee, P.-M. (2002). Behavioral model of online purchasers in e-commerce environment Electronic Commerce Research, 2(1-2), 75-85.

23. Sicilia, M., Ruiz, S., \& Reynolds, N. (2006). Attitude formation online: How the consumer's need for cognition affects the relationship between attitude towards the website and attitude towards the brand. International journal of market research, 48(2), 139-154.

24. Bailey, P., Thomas, P., \& Hawking, D. Does brandname influence perceived search result quality? Yahoo!, Google, and webkumara. In Proceedings of the 12th Australasian document Computing Symposium, Melbourne, Australia, 2007

25. Bhattacharya, C. B., \& Sen, S. (2003). Consumer-company identification: A framework for understanding consumers' relationships with companies. The Journal of Marketing, 67(2), 76-88.

26. Axelrod, J. N. (1968). Attitude measures that predict purchase. Journal of Advertising Research, 8(1), 3-17.

27. Romaniuk, J., Sharp, B., Paech, S., \& Driesener, C. (2004). Brand and advertising awareness: A replication and extension of a known empirical generalisation. Australasian marketing journal, 12(3), 70-80.

28. Schechter, A. H. (1993). Measuring the value of corporate and brand logos. Design Management Journal, 4, 33-39.

29. Vartorella, W. (1990). Doing the bright thing with your company logo. Advertising age, 61(2), 31.

30. Henderson, P. W., \& Cote, J. A. (1998). Guidelines for selection or modifying logos. Journal of marketing, 62(2), 14-30.

31. Keller, K. L. (2007). Strategic brand management: Building, measuring, and managing brand equity (3rd ed.). Upper Saddle River: Prentice Hall.

32. Riel, C. B. M. v., \& Ban, A. v. d. (2001). The added value of corporate logos - an empirical study. European Journal of Marketing, 35(3/4), 428 - 440.

33. Descombe, M. (2003). The good research guide (2ed.). Philadelphia: Open University Press.

34. comScore (2004). Marketers take note: The elusive 18-34 year-old is habitually online.,

35. Li, D., Browne, G. J., \& Wetherbe, J. C. (2007). Online consumers' switching behavior: A buyerseller relationship perspective. Journal of Electronic Commerce in Organizations, 5(1), 30-42.

36. Spink, A., Jansen, B. J., Wolfram, D., \& Saracevic, T. (2002). From e-sex to e-commerce: web search changes. IEEE Computer, 35(3), 107-109.

37. Chen, S. (2001). Assessing the impact of the internet on brands. Brand Management, 8(4\&5), 288302.

38. Jansen, B. J., \& McNeese, M. D. (2005). Evaluating the effectiveness of and patterns of interactions with automated searching assistance. Journal of the american society for information science and technology, 56(14), 1480-1503.

39. Pang, B., \& Lee, L. (2008). Opinion mining and sentiment analysis. Foundations and Trends ${ }^{\circledR}$ in Information Retrieval, 2(1-2), 1-135.

40. Gibbs, G. R. (2002). Qualitative data analysis: Explorations with NVivo: Buckingham: Open University Press.

41. Church, K. W., \& Hanks, P. (1990). Word association norms, mutual information, and lexicography. Computational Linguistics, 16(1), 22-29.

42. comScore (2009). June 2009 U.S. Core search rankings.

43. Peter, J. (1989). Designing logos. Folio, 18(July), 139-141.

44. Mitta, B. (2006). I, me, and mine - how products become consumers' extended selves. Journal of consumer behaviour, 5(6), 550 - 562. 
45. Rohlfs, J. H. (2003). Bandwagon effects in high technology industries. Cambridge, MA.: MIT Press.

46. Holman, R. H. (1981). Apparel as communication. In E. Hirschman, \& M. Holbrook (Eds.), Symbolic consumer behavior (pp. 7-12). New York: Association for Consumer Research.

47. Sherif, M., \& Hovland, C. I. (1961). Social judgment: Assimilation and contrast effects in communication and attitude change. New Haven: Yale University Press.

48. Jansen, B. J., \& Solomon, L. Gender demographic targeting in sponsored search. In E. Mynatt, \& D. Schoner (Eds.), ACM Conference on Human Factors in Computing Systems, Atlanta, GA, 10-15 April 2010 (pp. 831-840) 


\section{APPENDIX}

Imagine that you want to buy flowers online for a special person. Identify a search engine that you would most likely use to search for an online store or place to buy these flowers. Please answer the following questions:

What is the name of the search engine that you identified above?

Why did you choose this one?

List your three favorite search engines (list only the one(s) you actually use)

(1) - most favorite

(2) - next favorite

(3) - next favorite

Why do you use these search engines and not others? (Check all that apply)
[ ] Can sort results
[ ] Dependable
[ ] Ease to Use
[ ] Familiarity
[ ] Reputation
[ ] Gives lots of results [ ] Habit
[ ] Interface
[ ] My friends use it
[ ] Popular
[ ] Powerful
[ ] Trustworthy
[ ] Fast
[ ] Ones I know
[ ] Searching Features [ ] Useful Results
[ ] Gives me new results
[ ] Gives me results that I expect
[ ] Happy with these, no need to try others

Other(s)

\begin{tabular}{|c|c|}
\hline Search Engine Logo & $\begin{array}{l}\text { Directions: Look at the logo. Based on your } \\
\text { experiences with the search engine, if any, and the } \\
\text { logo,... }\end{array}$ \\
\hline The Agent Improved Information Retrieval System & $\begin{array}{l}\text { Please provide the first meaning or association that } \\
\text { comes to your mind by looking at the logo. } \\
\text { What is your overall impression of the search } \\
\text { engine? (For example, like/dislike, good/bad, } \\
\text { high/low quality, distinctive/not distinctive, and } \\
\text { interesting/uninteresting) } \\
\text { Have you used this engine before? (circle) Yes / No } \\
\text { If yes, do you currently use this engine? (circle) Yes / } \\
\text { No }\end{array}$ \\
\hline $0 \mathrm{ofl}$ & $\begin{array}{l}\text { Please provide the first meaning or association that } \\
\text { comes to your mind by looking at the logo. } \\
\text { What is your overall impression of the search } \\
\text { engine? (For example, like/dislike, good/bad, } \\
\text { high/low quality, distinctive/not distinctive, and } \\
\text { interesting/uninteresting) } \\
\text { Have you used this engine before? (circle) Yes / No } \\
\text { If yes, do you currently use this engine? (circle) Yes / } \\
\text { No }\end{array}$ \\
\hline
\end{tabular}




\begin{tabular}{|c|c|}
\hline Search Engine Logo & $\begin{array}{l}\text { Directions: Look at the logo. Based on your } \\
\text { experiences with the search engine, if any, and the } \\
\text { logo,... }\end{array}$ \\
\hline & $\begin{array}{l}\text { Please provide the first meaning or association that } \\
\text { comes to your mind by looking at the logo. } \\
\text { What is your overall impression of the search } \\
\text { engine? (For example, like/dislike, good/bad, } \\
\text { high/low quality, distinctive/not distinctive, and } \\
\text { interesting/uninteresting) } \\
\text { Have you used this engine before? (circle) Yes / No } \\
\text { If yes, do you currently use this engine? (circle) Yes / } \\
\text { No }\end{array}$ \\
\hline & $\begin{array}{l}\text { Please provide the first meaning or association that } \\
\text { comes to your mind by looking at the logo. } \\
\text { What is your overall impression of the search } \\
\text { engine? (For example, like/dislike, good/bad, } \\
\text { high/low quality, distinctive/not distinctive, and } \\
\text { interesting/uninteresting) } \\
\text { Have you used this engine before? (circle) Yes / No } \\
\text { If yes, do you currently use this engine? (circle) Yes / } \\
\text { No }\end{array}$ \\
\hline & $\begin{array}{l}\text { Please provide the first meaning or association that } \\
\text { comes to your mind by looking at the logo. } \\
\text { What is your overall impression of the search } \\
\text { engine? (For example, like/dislike, good/bad, } \\
\text { high/low quality, distinctive/not distinctive, and } \\
\text { interesting/uninteresting) } \\
\text { Have you used this engine before? (circle) Yes / No } \\
\text { If yes, do you currently use this engine? (circle) Yes / } \\
\text { No }\end{array}$ \\
\hline & $\begin{array}{l}\text { Please provide the first meaning or association that } \\
\text { comes to your mind by looking at the logo. } \\
\text { What is your overall impression of the search } \\
\text { engine? (For example, like/dislike, good/bad, } \\
\text { high/low quality, distinctive/not distinctive, and } \\
\text { interesting/uninteresting) } \\
\text { Have you used this engine before? (circle) Yes / No } \\
\text { If yes, do you currently use this engine? (circle) Yes / } \\
\text { No }\end{array}$ \\
\hline
\end{tabular}




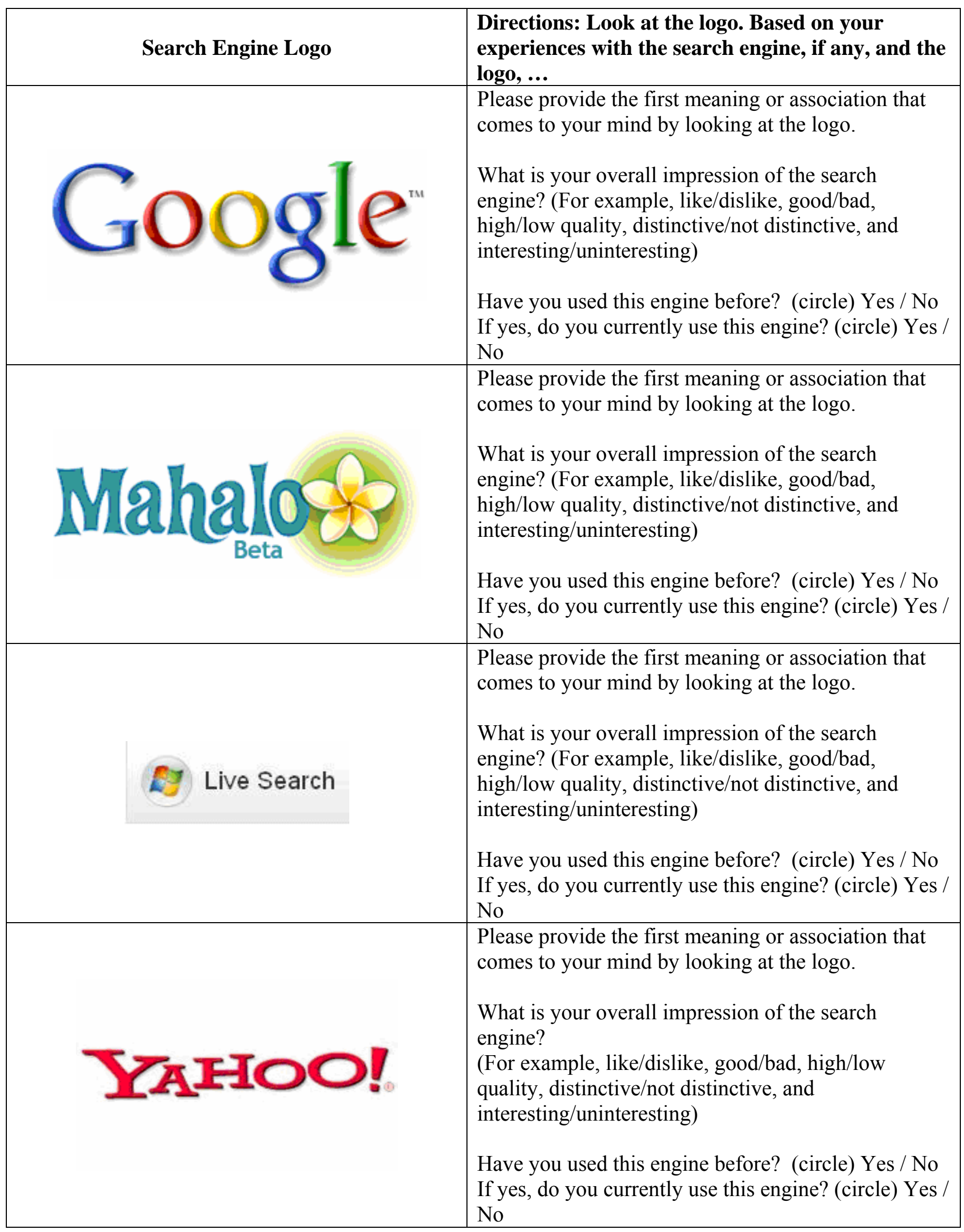


Note: at the time of the survey, Bing had not been released 